\title{
Physiological Markers and Reflex Pattern Progression in Individuals with Neurodevelopmental Deficits Utilizing the MNRI Method
}

\section{Trina Deiss ${ }^{1}$, Rebekah Meyers' ${ }^{1}$ Jordan Whitney ${ }^{2}$, Clayton Bell ${ }^{3}$, Tatiana Tatarinova4, Lorri Franckle ${ }^{5}$, Susan Beaven 6}

${ }^{1}$ United1Front Foundation, Minneapolis, MN, USA

${ }^{2} 3 \mathrm{M}$ Co., Minneapolis, MN, USA

${ }^{3}$ Department of Family Medicine, University of Tennessee Medical Center, Knoxville, TN, USA

${ }^{4}$ University of La Verne, La Verne, CA, USA

${ }^{5}$ Laser Health, Orlando, FL, USA

${ }^{6}$ St. Petersburg Free Clinic, St. Petersburg, FL, USA

Email: aversigg@sbcglobal.net

How to cite this paper: Deiss, T., Meyers, R., Whitney, J., Bell, C., Tatarinova, T., Franckle, L. and Beaven, S. (2019) Physiological Markers and Reflex Pattern Progression in Individuals with Neurodevelopmental Deficits Utilizing the MNRI Method. Neuroscience \& Medicine, 10, 30-54.

https://doi.org/10.4236/nm.2019.101003

Received: January 21, 2019

Accepted: March 18, 2019

Published: March 21, 2019

Copyright $\odot 2019$ by author(s) and Scientific Research Publishing Inc. This work is licensed under the Creative Commons Attribution International License (CC BY 4.0).

http://creativecommons.org/licenses/by/4.0/

\begin{abstract}
The physiological markers of 310 individuals aged 2 through 19 were evaluated for the effects of the Masgutova Neurosensorimotor Reflex Integration Method on their four body systems: respiratory, cardiovascular, digestive, and nervous systems of individuals with neurodevelopmental deficits-cerebral palsy $(\mathrm{CP})$, seizures, traumatic and acute brain injury, attention deficit and hyperactive disorders (ADD, ADHD), autism spectrum disorders, anxiety, post-trauma and post-traumatic stress disorders. We found that $53.33 \%$ of physiological markers and $66.67 \%$ of reflex patterns on the pre-test demonstrated to be poorly functioning. Both evaluation results showed statistically significant improvements after 8-days of intensive training using the Masgutova Neurosensorimotor Reflex Integration Method. Improvements according to $60.0 \%$ of the physiological markers positively correlated with functionality gains in $77.5 \%$ of reflex patterns in all four study groups compared to the control group, which did not receive the Reflex Integration training program (p-value $<0.05$ ). The magnitude of improvement depended upon the severity of symptoms indicating the essentiality for individualized training in accordance with the diagnosis and individual neurological deficits. Results of this study show that reflex integrative techniques can lead to a reduction of stress and other negative factors blocking health homeostasis, limiting perception, and causing dysregulation in behavior and emotions, especially fol-
\end{abstract}


lowing traumatic events. Positive changes in physiological markers and reflex pattern functions indicate potential benefits for survival and stress resiliency through supporting neuro-physiological and neuro-psychological aspects of overall health and well-being in individuals with neurological deficits.

\section{Keywords}

Physiological Markers, Cerebral Palsy, Autism, Brain Injury, Trauma, PTSD, Masgutova Neurosensorimotor Reflex Integration Method (MNRI)

\section{Introduction}

Masgutova Neurosensorimotor Reflex Integration Method (MNRI) was developed by Svetlana Masgutova in 1989 in Russia [1]. This approach offered a new paradigm on the enrichment of the concepts of how to bring primary reflexes into a state of integration. Researchers worldwide have investigated the impact of sensorimotor integration on the growth of nerve axons and dendrites, myelination, activation of genetic blueprints, and the awakening of motor memory [2] [3]-[10]. MNRI is used to treat individuals with certain types of sensorimotor reflex developmental deficits, behavior disorders, speech and language delays, and learning disabilities. The technique was brought to the USA in 1994 and has gradually become accepted by healthcare professionals in many other countries.

The MNRI method is designed to include both higher and lower nervous system activities as it relates to reflex integration. MNRI basic concepts replace the traditional theory of reflexes as primitive survival responses that become inhibited with normal development [11] [12] [13] [14]. The term "missing link" has been used by professionals from multidisciplinary backgrounds from all over the world to describe MNRI. This program is structured around the concept of reflexes as the basic unit and neurophysiological foundation for higher brain functioning. Furthermore, reflexes are the physical expressions of protective neurocortical responses to stress and danger. Another basic concept of MNRI includes the understanding of a reflex as a genetic neuro-code and unit for both automatic and conscious sensory-motor development. This concept allows re-examination in research of the relationship between primary sensory-motor development and physical, emotional, and cognitive skills. MNRI focuses on the healthy neurological development of the individual using re-patterning exercises which rebuild neurosensorimotor reflexes rather than focusing on specific neurological disorders and diseases. The term "re-patterning" within the MNRI theory means re-education, recoding, and rerouting the reflex nerve pathways specific for dynamic and postural reflex patterns (e.g. Babinski, Automatic Gait, Bauer Crawling, Hands Grasp, and others). MNRI exercises stimulate innate neuro-regulation mechanisms and enhances resiliency in the stress and immune systems [15] [16]. Re-patterning activates the extrapyramidal nervous system (peripheral nerves, spinal cord, brain stem, diencephalon) responsible for automatic mechanisms 
and processes, the extension of neural synapses, the growth of neural nets, myelination, and the creation of new nerve routing [2] [7] [8] [17].

Theoretical base of the MNRI approach includes:

1) Sensorimotor integration is an essential factor in human development [3] [4] [6] [9] [17] [18] [19] [20].

2) Motor development involves physical growth and differentiation with specific rules, stages, and dynamics necessary for the attainment of consciously formed skills and learning [5] [20] [21] [22].

3) The natural motor system is based on a foundation of integrated sensory perception, brain processing and corresponding motor pattern responses within a reflex circuit [3] [7] [19] [21].

4) In a healthy functioning neurosensorimotor system, natural movements serve both as survival mechanisms and the foundation for physical development [3] [6] [18] [21].

Natural learning is achieved through the integration of the primary motor, emotional [22] and cognitive spheres [20] [23] [24].

Within the medical, psychology, and pediatrics sciences there are many different programs that address developmental challenges and problems. Many of these methods offer interdisciplinary approaches including traditional forms of medical support (medications, surgical procedures, orthotics, etc.), Physical Therapy, Occupational Therapy, Speech-Language Therapy, Respiratory Therapy, Cognitive-Behavioral Therapy, Neurofeedback (Pitman, Shin, Rauch, 2001), Music Therapy, Massage Therapy, Hydrotherapy, dietary advice, and other alternative treatments including Bobath Neuro-Developmental Techniques and many others [13] [25]-[30].

Our study utilized the MNRI treatment process as adjunctive integrative therapy for patients with: 1) cerebral palsy (CP), seizures, traumatic and acute brain injury (TBI and ABI), 2) anxiety, post-trauma and PTSD, 3) attention deficit and hyperactive disorders (ADD/ADHD), and 4) Autism Spectrum Disorders (ASD). Previous research, clinical observations, and reflex evaluations of over 35,000 individuals who received the MNRI therapy programs indicate that this program facilitates neurodevelopment in individuals possessing various neurological deficits. The therapy enables them to reroute and improve their early movements, reflexes, coordination systems, and skills facilitating better functioning, development, and learning [15] [31] [32] [33] [34].

Previous MNRI studies described positive effects of the MNRI therapy program on immune system modulation of individuals with bronchitis [15] [31] and Down syndrome [32] [33] [34], brain mapping coherence of individuals with CP, TBI and other brain injuries [35] [36] [37] [38], behavioral and emotional regulation, improvements of communication, language and cognitive skills in individuals with the ASD [39] [40] and other disorders. The MNRI therapy program is based on the supposition that impaired reflex circuits can be reconstructed through the retraining of reflexes which appears to result in the 
awakening of genetic sensorimotor memory in individuals. Along with these neurodevelopmental changes, significant positive changes have also been observed in physical strength and immune activity, as well as improvement in cognitive, emotional, social, and motor abilities [32]-[38]. This article further advances this topic and addresses the effectiveness of MNRI therapy using the evaluation of physical markers and Reflex Assessment pre- and post-conference attendance.

This study completed during 2016-2017 evaluates the effect of the MNRI Neurosensorimotor Reflex Integration Therapy modality in 310 individuals aged 2 - 19. The research approached four groups of individuals with neurological deficits: Study Group 1-CP, seizures, traumatic brain injury (TBI) and acquired brain injury (ABI) (n = 49); Study Group 2-ADD/ADHD (n = 104); Study Group 3-anxiety, post-trauma and PTSD (n=62); and Study Group 4-ASD $(\mathrm{n}=95)$, and one Control Group of individuals with typical development $(\mathrm{n}=$ 241-participated in reflex Assessment). Our study also presents comparative data on profiles of physiological marker norms (age related) and functionality of reflex patterns.

The research (experimenter) bias was controlled by having two independent groups of researchers: the first group included professionals carrying out the testing procedures (nurses and doctors) and the second group included analytical professionals (scientists with Ph.D. degrees in medical sciences) who analyzed the pre and post-intervention data. These professionals were not in communication. There was no communication between statisticians in the two groups as well.

Goal: The purpose of this research was to investigate the impact of the MNRI Reflex Integration Method on four body systems: respiratory, cardiovascular, digestive, and nervous systems. The comparative analysis involved participants with neurological deficits in four groups: $C$, seizures, TBI and ABI 1); ADD/ADHD 2); anxiety, post-trauma and PTSD 3); and ASD 4) and was carried out to analyze: a) physiological markers, b) functionality of reflex patterns; and c) correlation between physical markers and expression of reflex pattern. The latter may reveal underlying reasons for stress including the regulatory issues within "HPA-alarm system" (over-reactive or hypo-active).

\section{Materials and Methods}

\subsection{Research Design}

This study reports the results of a study conducted from January 2016-June 2017 with 310 individuals during MNRI trainings programs at Family Conferences. The study consisted of three stages:

1) First stage of research:

a) examinations of physiological markers with comparison to norm (AMA; https://www.ama-assn.org) and reflex parameters assessment in individual in $\operatorname{Study}(\mathrm{n}=310)$ and Control $(\mathrm{n}=241)$ groups; 
b) the MNRI therapeutic program for individuals in Study Group;

2) Second stage of research was oriented on processing of the data (statistic and quality analysis);

3) Third stage of research went through analysis and interpretation of the data. The processing of the study data was done by scientists who were unaware of patients' diagnosis, age and their respective results pre and post treatment intervention. Furthermore, researchers did not know the MNRI specialists, the individuals in the control or neurodevelopmental atypical group, or the researchers in the other analysis group.

Details of the evaluation method are presented below.

MNRI Family Conference programs. Three hundred and ten patients aged 2 - 19 years diagnosed with CP, seizures, TBI, ABI, anxiety, PTSD, ADD/ADHD and ASD underwent the MNRI training with repatterning exercises at MNRI Family Conferences from January 2016 through June 2017. The MNRI therapeutic process included six consecutive progressive modules chosen in such a way as to affect various physiological and nervous system functions (sensory-proprioceptive-motor system, reflex parameters) to retrieve/restore the reflex circuit and move them towards neurological maturation.

The MNRI Family Conference sessions were focused on improving the sensory-motor milestones, motor programming, planning and control, regulation of excitatory and inhibitory processes, and cognitive skills through working with the reflex neurosensory and motor circuit components. Each session lasted 50 minutes with a 10-minute break between three sessions in the morning, 1.5-hour lunch break and 3 sessions after lunch followed by group lectures and training for caregivers in the evening. The MNRI Family Conference lasted 8 days (4 days of active treatment intervention followed by a one-day break, then 4 more days of treatment). The conference training sessions were provided by MNRI certified specialists.

Daily treatment sessions included 6 of the 7 following modalities:

1) Neuro-Structural Reflex Repatterning-Improves the functions of reflexes responsible for postural control, spine flexibility, abdomen, and neck and limbs muscular tone regulation; also facilitates feelings of protection and of being secure (HPA-stress-axis regulation), thus increasing stress resiliency.

2) NeuroTactile Integration-Regulation and normalization of tactile sensitivity (hyper or hypo), coordination and integration of receptors, skin dermatomes, overall peripheral and central nervous system support for reflex repatterning and integration, stress and anti-stress hormonal regulation.

3) Archetype Movements Integration-Enhancement of the primary biomechanics of movement patterns (extension, flexion, rotation, stretching, compression, and other supporting structural aspects of numerous reflex patterns; development of automatic and consciously learned motor abilities and skills; postural and motor control including the secondary improvements in speed of perception, focus and memory, sensory-motor integration, and cognitive functions. 
4) Breathing Reflex Integration-Regulation and normalization of breathing reflex patterns, residual volume of the lungs for creating sufficient protection and survival (HPA-stress-axis regulation), increasing stress resiliency.

5) Stress and Traumatic Stress Release-Working with reflex patterns that impact the HPA stress-axis for letting go of past negative stress and traumatic events via normalization of stress hormones and neurotransmitters.

6) Proprioceptive-Cognitive Integration-Improving the proprioceptive-vestibular (balance) system and related reflexes for support of postural and motor control, with secondary improvement in cognitive functions.

7) Oral-Motor/Visual-Auditory Reflexes Integration-Improving oral-motor skills, articulation and speech abilities, as well as visual and auditory functions.

\subsection{Demographic Data}

The research group was composed of four neuro-atypical study groups with a total of 310 individuals aged 2 - 19 years having different developmental challenges and neurological deficits. The group included 18 individuals aged 2 - 3; 85 individuals aged $4-5 ; 87$ individuals aged 6 - 9; 45 individuals aged $10-13 ; 43$ individuals aged 14 - 15; and 32 individuals aged 16 - 19. These individuals were included into the following groups: 1) Study Group 1-CP, ABI, TBI and seizures 15.81\% ( $=49)$; 2) Study Group 2-ADHD, ADD 33.55\% ( $=104) ; 3$ ) Study Group 3-anxiety, post-trauma, PTSD 20\% ( $\mathrm{n}=62$ ); and D) ASD 30.64\% $(\mathrm{n}=95)$. All these individuals received the 8-day MNRI Reflex Integration treatment intervention. The Control Group $(\mathrm{n}=241)$ included individuals with normal, typical developmental, aged 2 - 19 which did not receive the MNRI treatment intervention. The reflex assessment was done for baseline measurement and was repeated in 9 days as was done with the Study Group.

Inclusion Criteria. The study did not include children with acute inflammatory diseases, as well as with chronic eczema and atopic dermatitis during the exacerbation.

Evaluation Methods. The design of this study includes two clinical evaluations (see A and B), statistical analysis (C), and the MNRI ${ }^{\circledR}$ treatment program.

A) Physiological Markers Panel and Examination. Physiological markers included: blood pressure, heart rate, pulse ox, all pulses including pedal pulses, Peak Flow, lung sounds, bowel sounds, and PERRLA (Pupils Equal, Round, React to Light, Accommodation). A physical exam is imperative to the diagnostic and continuum of care for a patient. "In an observational study regarding the impact of the physical exam on diagnosis and subsequent treatment, [41] noted that in $26 \%$ of patients, a skilled physical exam provided a pivotal finding that changed the patient's diagnosis and treatment. Furthermore, in almost half of these patients, diagnosis would not have been determined through common diagnostic practices. Therefore, the physical exam findings based on specific markers were critical to making and confirming an accurate diagnosis quickly" [41].

The physicals performed at the MNRI ${ }^{\circledR}$ Family Conferences were not in- 
tended for data comparison exclusively and not for medical diagnostic purposes. Physicals were performed on 310 participants who attended the Masgutova Family conferences across the USA. These conferences were 8-day conferences (4 days of sessions, one day of rest and 4 more days of sessions) with intensive MNRI treatments (6 fifty-minute sessions) provided each day. Participants would receive neurosensorimotor reintegration exercises performed by certified core specialists trained in this modality. The Family Conference participants had medical diagnosis of $\mathrm{ADD} / \mathrm{ADHD}$, cerebral palsy and seizures, $\mathrm{ABI}, \mathrm{TBI}$, anxiety, post-trauma, PTSD and autism where eligible for this study. The physicals were performed prior to the MNRI ${ }^{\oplus}$ treatment and repeated on the last $\left(9^{\text {th }}\right)$ day of the Family Conference. The physicals were administered by registered nurses and the Reflex Assessment was administered by Certified MNRI ${ }^{\oplus}$ professional. All tests were performed according to the guidelines of the American Medical Association (AMA; https://www.ama-assn.org). Below is the list of collected measurements:

1) Blood pressure was measured to determine the level of systolic and diastolic pressure.

2) Heart rate was achieved by taking pulse for 60 seconds.

3) Oxygen saturation was measured by finger pulse oximetry.

4) Peak flow (peak expiratory flow rate or expiratory flow) measures the expiratory force of the lungs. Three attempts were performed, and only the highest measurement was recorded. The meter utilized was a non-rebreather hospital grade meter.

5) Heart sounds were auscultated for murmurs and rhythm.

6) Lung sounds, or breath sounds were auscultated with a stethoscope on both anterior and posterior sides of the chest. Assessment included listening to full inspiration and expiration cycle, pitch, duration, and sounds. Lung sounds are based on the sounds in lobes and to rule out respiratory concerns that could impact other parameters such as peak flow or $\mathrm{O} 2$.

7) Bowel sounds were auscultated by listening to the abdomen with a stethoscope in all four quadrants of the abdomen to determine bowel activity indicative as hypo-active, hyper-active, or active. Bowel sounds have parameters of sounds per minute ration (a patient meets this criterion or not). Note: important measure for bowel activity which many individuals have struggles with.

8) Pulses were palpated for timing, strength, bilateral equality.

9) PERRLA (Pupils Equal, Round and Reactive to Light and Accommodation) was performed with a pen light to measure the size and shape of the pupils, the timing and equality of their reaction to light, as well as the eyes ability to accommodate.

B) The MNRI Reflex Assessment. The MNRI ${ }^{\circledR}$ Reflex evaluation [16] [42] scoring 30 reflex patterns (diagnostic markers coded X1 - X30) was conducted twice for each study participant (prior to treatment intervention and after intervention on day 9) in the Study groups that completed eight days of MNRI, and 
in the Control Group that did not go through the MNRI ${ }^{\oplus}$ treatment program (see Table 3). The $\mathrm{MNRI}^{\circ}$ Reflex Assessment evaluates the level of neurophysiological maturity of the reflex patterns in relation to age, and also determines deviations in neurological development related to specific areas of neurological functioning [16]. Examples include the Core Tendon Guard reflex, which is strongly connected with the "alarm system" or HPA-stress-axis (hypothalamus-pituitary gland-adrenals). HPA Axis dysregulation has been shown to correspond with dominance of the sympathetic nervous system over the parasympathetic in stress and trauma [43]. Another reflex, Hands Pulling, allows an individual to sit up from prone position. If Hands Pulling reflex pattern is not matured, it can lead to poor coordination of core flexion and visual convergence [16]. Neurological reflex deviations are associated with chronic stress, illness, traumas, and overall developmental delays. Furthermore, poorly developed reflex patterns affect the maturation/myelination of the nervous system, particularly the pyramidal nervous system. Reflex Assessments used in this study included the following patterns: Robinson Hand Grasp, Hands Supporting, Spinal Galant, Spinal Perez, Asymmetrical Tonic Neck, Leg Cross Flexion-Extension, Bauer Crawling, and the Moro Response. Insights gained from reflex patterns and their physiologically relevant functions are important for success of re-patterning exercises. Reflex patterns also provide precise information on developmental deficits in the primary neurosensorimotor area and in the self-regulation mechanisms. Thus, the data gained on the reflex assessment can help to develop individualized correctional treatment plans essential for each unique participant [16].

The Reflex Assessment provided the following specific scores for every tested reflex:

1) sensory-motor coordination,

2) direction of the response,

3) intensity (muscle tone regulation),

4) timing/dynamics of the response, and

5) symmetry [16].

Every parameter was tested according to the aforementioned features. For example, evaluation of the first parameter of "sensory-motor coordination" (sensory stimulus and bio-mechanical aspect of the motor response) in the Hands Grasp Reflex contains four features with corresponding sub-scores: 1) tactile stimulation on the base of a closed palm in a more intense proprioceptive way to activate palm flexors should trigger a stronger grasp response, 2) all fingers, thumb between index and middle fingers should close, 3) elbow must be capable for relaxed extension in front of the body for 100 degrees, and shoulder for 90 or more degrees, 4) arm/palms are directed horizontally to the ground (no abnormal abduction/adduction in the wrist joint must be present). Each reflex pattern used in this study was evaluated using the four parameters described below.

The main parameters for the evaluation include [16]: 
1) sensory-motor circuit: the neurophysiological circuit components of coherence include sensitivity to sensory stimulus and physical response to the stimulus. This includes a motor or postural response to a specific sensory or sensory-proprioceptive stimulus (coherent links between sensory and motor neurons).

2) sequence and direction: the identity of the motor-postural response in comparison to the "ideal model" response including movement and posture (coordinated work of the alpha and gamma motor neurons).

3) latency of nerve transmission: the time frame of the response that must happen within a fraction of a second after stimulation for effective response to fulfil its protective function including the tone of muscles, ligaments and tendons (scored as normal, dysfunctional, pathological, hyper or hypo-active or a-reflexia/absence).

4) intensity: proper muscle tone regulation in the motor response proportional to intensity of the sensory stimulus scored as normal, hyper or hypo-active, or a-reflexia/absence.

5) symmetry: the equality of the circuit function, sequence/direction, latency, and intensity of the response on the right and left sides of the body [35] [44] [45] [46] [47].

Scores were assigned on a continuous scale of $0-4$ points with 4 indicating a full display of a parameter, and 0 indicating non-display of the parameter, resulting in a possible maximum total score of 20 points for each reflex on a scale of 0 to 20 with 20 points indicating the highest level of maturity or integration (Table 1). A normal response should score 16 - 17.99 points, 12 - 15.99 points is suboptimal, 10 - 11.99 points represent the borderline between functional and dysfunctional, and any reflex scoring less than 10 is dysfunctional. This scoring

Table 1. Physiological Markers in neuroatypical MNRI Treatment Group.

\begin{tabular}{|c|c|c|c|c|c|c|c|c|c|c|c|}
\hline \multirow{4}{*}{$\#$} & \multirow{2}{*}{$\begin{array}{c}\text { Testing Markers } \\
\text { Symptoms }\end{array}$} & \multicolumn{10}{|c|}{$\begin{array}{l}\text { Average Changes in Physiological Markers in Pre- and Post-tests after the Use of the MNRI }{ }^{\circledR} \text { Reflex } \\
\text { Integration Program for Participants with Neurological Deficits by Subgroups: }\end{array}$} \\
\hline & & \multicolumn{2}{|c|}{$\begin{array}{l}\text { CP, Seizure, TBI, } \\
\text { ABI }\end{array}$} & \multicolumn{2}{|c|}{ ADD/ADHD } & \multicolumn{2}{|c|}{$\begin{array}{l}\text { Anxiety disorders and } \\
\text { post-trauma }\end{array}$} & \multicolumn{2}{|c|}{ Autism disorder } & \multicolumn{2}{|c|}{$\begin{array}{l}\text { Average } \\
\text { for all Study groups }\end{array}$} \\
\hline & \multirow[t]{2}{*}{ Group } & \multicolumn{2}{|c|}{$\begin{array}{l}\text { Study } 1 \\
(\mathrm{n}=49)\end{array}$} & \multicolumn{2}{|c|}{$\begin{array}{c}\text { Study } 2 \\
(\mathrm{n}=104)\end{array}$} & \multicolumn{2}{|c|}{$\begin{array}{l}\text { Study } 3 \\
(\mathrm{n}=62)\end{array}$} & \multicolumn{2}{|c|}{$\begin{array}{l}\text { Study } 4 \\
(\mathrm{n}=95)\end{array}$} & \multicolumn{2}{|c|}{$(\mathrm{n}=310)$} \\
\hline & & Pre-test & Post-test & Pre-test & Post-test & Pre-test & Post-test & Pre-test & Post-test & Pre-test & Post-test \\
\hline \multirow[t]{2}{*}{1} & Pulse (bpm) & $\underline{93.47^{*}}$ & $\underline{83.21^{*}}$ & 83.25 & 80.38 & $\underline{83.75^{*}}$ & $\underline{75.31^{*}}$ & $\underline{85.64^{*}}$ & $\underline{79.11^{*}}$ & $\underline{86.52^{*}}$ & $\underline{79.5^{*}}$ \\
\hline & $C D \pm$ & $\underline{3.1}$ & $\underline{3.3}$ & 4.3 & 3.1 & $\underline{2.25}$ & $\underline{2.1}$ & $\underline{1.6}$ & $\underline{2.8}$ & $\underline{3.5}$ & $\underline{3.3}$ \\
\hline \multirow[t]{2}{*}{2} & Pulse Ox (\%) & $97.4 \%$ & $97.3 \%$ & $97 \%$ & $97.5 \%$ & $98 \%$ & $98 \%$ & $97 \%$ & $98 \%$ & $97.35 \%$ & $97.7 \%$ \\
\hline & $C D \pm$ & 4.5 & 3.9 & 5.5 & 4.7 & 4.4 & 3.8 & 5.8 & 6.1 & 6.2 & 5.1 \\
\hline \multirow[t]{2}{*}{3} & Systolic (bpm) & 93.41 & 94.63 & 101.43 & 99.59 & $\underline{107.3^{*}}$ & $\underline{95.14^{*}}$ & 97.37 & 98.27 & 99.87 & 96.9 \\
\hline & $C D \pm$ & 3.9 & 4.5 & 6.1 & 5.9 & $\underline{4.4}$ & $\underline{3.2}$ & 3.9 & 4.7 & 5.5 & 5.7 \\
\hline \multirow[t]{2}{*}{4} & Diastolic (bpm) & 64.54 & 62 & $\underline{72^{*}}$ & $\underline{61.5^{*}}$ & 66.55 & 68.5 & 63.6 & 66 & 66.67 & 64.5 \\
\hline & $C D \pm$ & 3.2 & 2.9 & $\underline{2.9}$ & $\underline{2.7}$ & 3.6 & 3.9 & 2.9 & 3.6 & 3.3 & 3.2 \\
\hline
\end{tabular}


T. Deiss et al.

\begin{tabular}{|c|c|c|c|c|c|c|c|c|c|c|c|}
\hline \multicolumn{12}{|c|}{ Continued } \\
\hline \multirow[t]{2}{*}{5} & Temperature & 98,51 & 98.46 & 98.7 & 96.88 & 98.25 & 98.36 & 97.9 & 98.1 & 98.34 & 92.95 \\
\hline & $C D \pm$ & 4.6 & 3.9 & 5.5 & 3.9 & 4.6 & 4.9 & 5.1 & 5.3 & 4.8 & 4.3 \\
\hline \multirow[t]{2}{*}{6} & Bowel Sound Score & $\underline{43.37^{*}}$ & $\underline{98.98^{*}}$ & $\underline{55.94^{*}}$ & $\underline{96.63^{*}}$ & $\underline{76.57^{*}}$ & $\underline{100^{*}}$ & $\underline{73.14^{*}}$ & $\underline{100^{*}}$ & $\underline{62.25^{*}}$ & $\underline{98.9^{*}}$ \\
\hline & $C D \pm$ & $\underline{2.6}$ & $\underline{5.5}$ & $\underline{3.1}$ & $\underline{4.8}$ & $\underline{3.45}$ & $\underline{5.4}$ & $\underline{3.3}$ & $\underline{4.13}$ & $\underline{2.8}$ & $\underline{4.5}$ \\
\hline \multirow[t]{2}{*}{7} & Breath Sound Score & $\underline{83.67^{*}}$ & $\underline{93.37^{*}}$ & 93.55 & 97.35 & $\underline{88.75^{*}}$ & $99.3^{*}$ & 89.84 & 98.68 & $\underline{88.95}$ & $\underline{97.17}$ \\
\hline & $C D \pm$ & $\underline{4.4}$ & $\underline{3.2}$ & 5.5 & 6.5 & $\underline{4.7}$ & $\underline{5.1}$ & 3.8 & 4.9 & $\underline{3.1}$ & $\underline{4.9}$ \\
\hline \multirow[t]{2}{*}{8} & Peak Expiratory Flow & $\underline{178.75^{*}}$ & $\underline{219.41^{*}}$ & $\underline{281.21^{*}}$ & $\underline{336.72^{*}}$ & $200.76^{*}$ & $\underline{267.26^{*}}$ & $\underline{203.33^{*}}$ & $\underline{244.52^{*}}$ & $\underline{216.01^{*}}$ & $\underline{266.97^{*}}$ \\
\hline & $C D \pm$ & $\underline{10.1}$ & $\underline{14.5}$ & $\underline{12.4}$ & $\underline{18.4}$ & $\underline{14.4}$ & $\underline{18.9}$ & $\underline{11.7}$ & $\underline{14.8}$ & $\underline{14.7}$ & $\underline{18.8}$ \\
\hline \multirow[t]{2}{*}{9} & Pedal Dedis Score & $82.29^{*}$ & $90.63^{*}$ & $\underline{86.5^{*}}$ & $\underline{100^{*}}$ & 96.46 & 100 & $\underline{82.36^{*}}$ & $\underline{100^{*}}$ & $\underline{86.9^{*}}$ & $\underline{97.65^{*}}$ \\
\hline & $C D \pm$ & 4.9 & 4.1 & $\underline{4.3}$ & $\underline{6.8}$ & 4.4 & 5.8 & $\underline{3.7}$ & $\underline{5.2}$ & $\underline{3.6}$ & $\underline{4.1}$ \\
\hline \multirow[t]{2}{*}{10} & Pedal Tibial Score & $\underline{81.25^{*}}$ & $\underline{93.75^{*}}$ & $\underline{89^{*}}$ & $\underline{100^{*}}$ & 95.99 & 100 & $\underline{82.97^{*}}$ & $\underline{100^{*}}$ & $\underline{87.3^{*}}$ & $\underline{98.43^{*}}$ \\
\hline & $C D \pm$ & $\underline{3.1}$ & $\underline{5.2}$ & $\underline{3.8}$ & $\underline{5.5}$ & 5.5 & 6.3 & $\underline{3.7}$ & $\underline{5.7}$ & $\underline{3.4}$ & $\underline{4.6}$ \\
\hline \multirow[t]{2}{*}{11} & Skin Temperature Score & $\underline{100^{*}}$ & $\underline{84.31^{*}}$ & $81.87^{\star}$ & $100^{*}$ & 83.15 & 87.5 & $\underline{83.3^{*}}$ & $\underline{100^{*}}$ & $\underline{87.08^{*}}$ & $\underline{92.95^{*}}$ \\
\hline & $C D \pm$ & $\underline{5.2}$ & $\underline{3.6}$ & 3.7 & 6.4 & 4.11 & 4.7 & $\underline{2.9}$ & $\underline{5.3}$ & $\underline{2.9}$ & $\underline{4.12}$ \\
\hline \multirow[t]{2}{*}{12} & Pupils Equal Score & $100^{*}$ & $93.88^{\star}$ & 98.08 & 100 & 99.13 & 100 & 97.37 & 100 & 98.64 & 98.47 \\
\hline & $C D \pm$ & 2.3 & 2.3 & 3.3 & 5.8 & 4.8 & 6.1 & 2.8 & 4.4 & 4.4 & 5 \\
\hline \multirow[t]{2}{*}{13} & Round Score & 100 & 100 & 100 & 100 & 100 & 100 & 100 & 100 & 100 & 100 \\
\hline & $C D \pm$ & 4.2 & 5.1 & 5.2 & 5.1 & 3.4 & 2.7 & 3.8 & 4.5 & 2.9 & 3.8 \\
\hline \multirow[t]{2}{*}{14} & Reactivity Score & 92.11 & 97.45 & 93.27 & 100 & $\underline{84.98^{*}}$ & $\underline{98.85^{*}}$ & $\underline{82.46^{*}}$ & $\underline{97.79^{*}}$ & $\underline{88.2^{*}}$ & $\underline{98.52^{*}}$ \\
\hline & $C D \pm$ & 4.5 & 4.7 & 3.9 & 5.5 & $\underline{2.3}$ & $\underline{4.1}$ & $\underline{2.9}$ & $\underline{3.9}$ & $\underline{2.9}$ & $\underline{3.5}$ \\
\hline \multirow[t]{2}{*}{15} & Accommodate Score & $\underline{62.5^{*}}$ & $\underline{43.37^{*}}$ & $\underline{82.86^{*}}$ & $\underline{93.75^{*}}$ & $\underline{51.98^{*}}$ & $\underline{87.13^{*}}$ & $\underline{53.95^{*}}$ & $\underline{74.26^{*}}$ & $\underline{62.82^{*}}$ & $\underline{74.62^{*}}$ \\
\hline & $C D \pm$ & $\underline{3.2}$ & $\underline{2.7}$ & $\underline{3.3}$ & $\underline{4.3}$ & $\underline{2.8}$ & $\underline{4.7}$ & $\underline{2.6}$ & $\underline{4.6}$ & $\underline{3.3}$ & $\underline{4.1}$ \\
\hline \multirow{2}{*}{\multicolumn{2}{|c|}{ Number of markers in norm }} & \multicolumn{2}{|c|}{8} & \multicolumn{2}{|c|}{7} & \multicolumn{2}{|c|}{8} & \multicolumn{2}{|c|}{7} & \multicolumn{2}{|c|}{6} \\
\hline & & \multicolumn{2}{|c|}{0.7} & \multicolumn{2}{|c|}{0.4} & \multicolumn{2}{|c|}{0.5} & \multicolumn{2}{|c|}{0.6} & \multicolumn{2}{|c|}{0.5} \\
\hline \multirow{2}{*}{\multicolumn{2}{|c|}{ Number of Markers Deviated }} & \multicolumn{2}{|c|}{7} & \multicolumn{2}{|c|}{8} & \multicolumn{2}{|c|}{7} & \multicolumn{2}{|c|}{8} & \multicolumn{2}{|c|}{9} \\
\hline & & & .5 & & 63 & & 7 & & & & \\
\hline $\begin{array}{r}\text { Nur } \\
\text { Si }\end{array}$ & $\begin{array}{l}\text { ber of Markers Improved } \\
\text { nificantly "*” }(\alpha=0.05)\end{array}$ & $9^{*}($ & $\left(2^{* *}\right)$ & $7^{\star}$ & $\left.3^{* *}\right)$ & & $\left.3^{* *}\right)$ & $9^{*}$ & $2 * *$ & & \\
\hline & lose to Significant "**»" & 0. & .45 & & 38 & & 56 & & & & \\
\hline
\end{tabular}

system has been validated by mathematical statistical research carried out at the Medical University of Poland by Professor A. Krefft [35] [48], and ANOVA test (IBM SPSS Statistics Grad Pack 22.00); results were considered statistically significant with $\mathrm{p}$ values $(M \pm \mathrm{SD})$ less than 0.001 and interpreted as significant, and not significant with $\mathrm{p}>0.05$. The assessed data was analyzed comparative to the child's age, neurological norms and abnormality features.

Reflex patterns were further categorized according to body movement planes, with ten patterns in each, corresponding to sagittal (medial-lateral), horizontal (superior-inferior), and dorsal (anterior-posterior) body movement planes [35]. 


\subsection{Statistical Analysis}

Statistical analysis was accomplished with parametrical and non-parametrical basic statistics with the use of the Mann-Whitney U-test and Wilcoxon test and a standard statistical software package for Windows 7 (StatSoft 7.0), Microsoft Excel and Win MDI software. The differences were considered as significant at $\mathrm{p}$ $<0.05$.

\section{Results}

\subsection{Physiological Markers Panel}

All four neuro-atypical study groups receiving the MNRI Reflex Integration Program demonstrated statistically significant improvements from pre- to post-intervention assessment in markers that originally deviated at the baseline (Table 1). The results were compared to the control group according to the age norm. Individuals in each study group were below the norm according to 8 out of 15 physiological markers (53.33\%). Nine (60.0\%) out of these 15 markers showed statistically significant improvement after the MNRI Reflex Integration program (Table 1 ).

Various improvements to measured physiological markers can be seen in all individual neuro-atypical study groups as well as the collective average amongst all study groups. Collective average of study group results yielded progress in six categories relating to the physiological markers: bowel sounds, peak expiratory flow, pedal dedis pulse, pedal tibial pulse, as well as ocular pupil reactivity and accommodation with statistical significance $\alpha=0.05$. Scores in pulse, breath sounds, and skin temperature also showed improvement.

On average, nine out of fifteen (60.0\%) physical markers above with certain differences in individual groups demonstrate significant improvements in the assessed markers of individuals after the use of the MNRI Program indicating simultaneous improvement of the stress reduction and regulation of homeostasis on a neurophysiological level.

The average results in all four study groups together show asignificant progress in nine (60.0\% out of 15) physiological markers: pulse, bowel sounds, breath sounds, peak expiratory flow, pedal dedis, pedal tibial, skin temperature, ocular reactivity and accommodation with statistical significance of $\mathrm{p}<0.05$. Scores in two (13.33\%) markers: diastolic pressure and temperature also improved as well.

The study found out that with only eight days of intervention using the MRNI therapy progresses, the physiological and vital markers improved significantly clinically and statistically in every of four study groups. When the data was analyzed all together as one group, the positive changes in markers were the same way valid and significant (Figure 1).

We discovered that the degree of improvement for physiological functions in individuals in the study groups depended on the diagnosis and severity of their neurological deficits. The results of the improvement in physiological markersin 
all groups combined (Figure 2), as well as in each study group (see Figures 2(A)-(D)), as described below.

The comparison of results in individuals in Study Group 1-CP, Seizure, TBI, and $A B I$ before and after the MNRI program show the progress in scores in the following nine (60.0\%) physiological markers: pulse, bowel sounds, breath sounds, peak expiratory flow, pedal dedis and tibial pulse, skin temperature, pupil equal score and ocular accommodation with statistical significance of $\mathrm{p}<$ 0.05 . Scores in two (13.33\%) additional markers: systolic blood pressure and reactivity, also improved substantially. The results of individuals in Study Group $2-A D D$ and $A D H D$ demonstrate improvement in the following seven $446.67 \%$ out of 15) physiological markers: diastolic blood pressure, bowel sounds, peak expiratory flow, pedal dedis, pedal tibial, skin temperature, and ocular accommodation with statistical significance of $\mathrm{p}<0.05$. Scores in three $(20.0 \%)$ markers of: pulse, reactivity, and breath sound also improved on noticeable level. The results of individuals in Study Group 3-Anxiety disorders and post-trauma after the MNRI training improved for seven (46.67\% out of 15) physiological markers: pulse, systolic (bpm), bowel sounds, breath sounds, peak expiratory flow, ocular reactivity and accommodation with statistical significance of $\mathrm{p}<$ 0.05. Scores in three (20\%) markers: pedal dedis, pedal tibial, skin temperature also improved on substantial level. The results of individuals in Study Group 4-Autism Disorder demonstrates a progress in nine (60.0\% out of 15) physiological markers: pulse, bowel sounds, breath sound, peak expiratory flow, pedal dedis, pedal tibial, skin temperature, ocular reactivity and accommodation with

\section{Before and after average values for all Study groups}

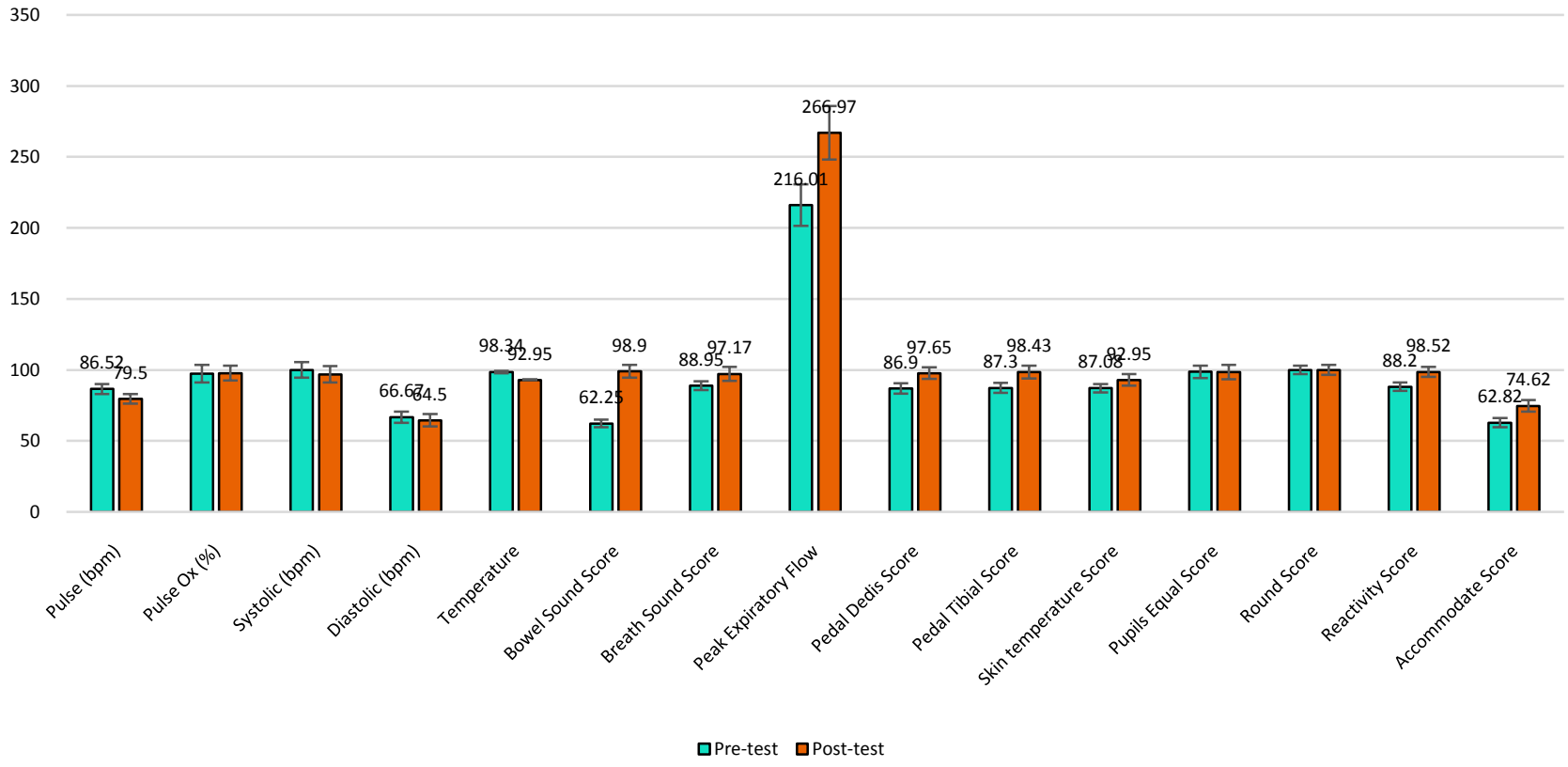

Figure 1. Summary Results of Average Changes in Physiological Markers in Participants, averaged across all of Four Groups of Neurological deficits before and after the MNRI Reflex Integration Program. 

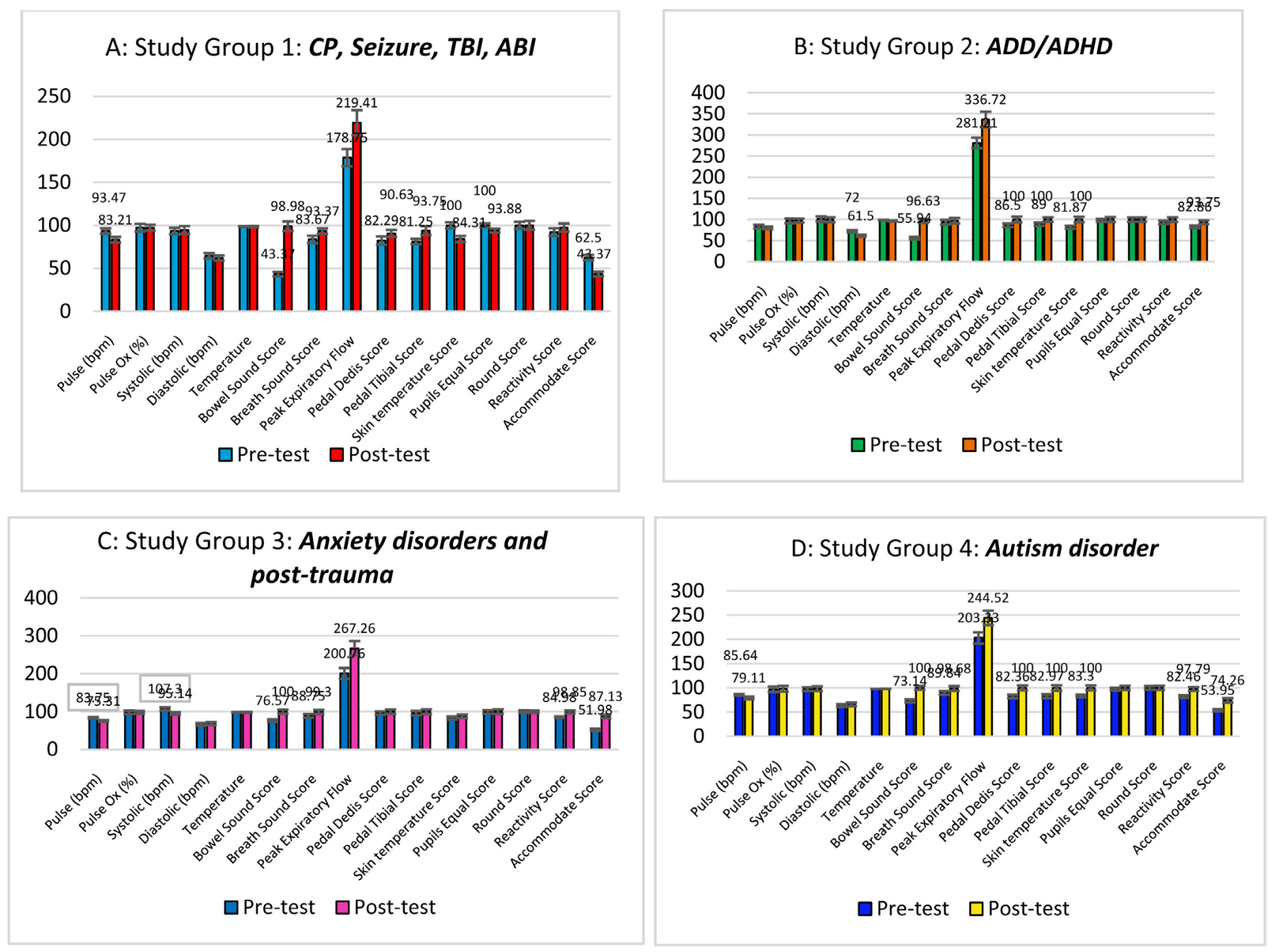

Figure 2. Results on individuals in Study Groups 1 - 4. (A) In the Study Group one CP, Seizure, TBI, and ABI before and after treatment show improvement in pulse, bowel sounds, breath sounds, peak expiratory flow, pedal dedis and tibial pulse, skin temperature, pupil equal score and ocular accommodation. (B) Results in the Study Group 2 (ADD and ADHD) demonstrated improvement in seven markers: diastolic blood pressure, bowel sounds, peak expiratory flow, pedal dedis, pedal tibial, skin temperature, and ocular accommodation. The results of individuals in the Study Group 3 (C) Anxiety disorders and post-trauma after the MNRI training improved for seven (46.67\% out of 15) physiological markers: pulse, systolic (bpm), bowel sounds, breath sounds, peak expiratory flow, ocular reactivity and accommodation. Results of individuals in the Study Group 4 (D) Autism Disorder demonstrate a progress in nine (60.0\% out of 15) physiological markers: pulse, bowel sounds, breath sound, peak expiratory flow, pedal dedis, pedal tibial, skin temperature, ocular reactivity and accommodation.

statistical significance of $\mathrm{p}<0.05$. Scores in two (13.33\%) markers: diastolic pressure and pupils equal also improved as well. The improvement in physiological markers correlate with each other and show positive impact of the MNRI ${ }^{\circledR}$ Program on the HPA-stress-axis (hypothalamic-pituitary-adrenal) and improved stress resiliency.

The HPA axis is responsible for the neuroendocrine adaptation necessary for the proper functioning of the stress response system and the normal functioning of the central nervous and endocrine systems. The HPA axis is the main biochemical pathway where information is transmitted from one area of the body to the next via chemical messengers. Any deviation of the homeostatic state such as an alarming sensory stimulus, emotional excitement, energy deficits or emer- 
gency events alarms the hypothalamus. These inputs are interpreted as perceived stress and can switch the stress response chain into action. This system is directly responsible for the neuroendocrine adaption to the stress response and regulates many body processes. The improvement in functioning of the HPA axis is imperative for regulating many homeostatic systems in the body, including the metabolic system, cardiovascular, immune, reproductive and central nervous systems. Another reason for the need to have the HPA axis working properly is that it is responsible for integrating the physical and psychosocial factors necessary to allow a person to effectively adapt to their environment and optimize survival. In case the HPA-axis cannot be regulated to overcome a challenge and is chronically exposed to a perceived threat, the system can become fatigued and lose its innate ability to optimally serve the nervous system or over-all health of the individual. Parents and their helping professionals of participants reported increased stress resiliency, improvements in physical strength and activity, as well as motivation for cognition and desire to imitate communication.

\subsection{Reflex Assessment}

Reflex functionality improved in individuals with neurological deficits in all four groups, and particularly, in: 1) Study Group 1 (CP, seizure, TBI and ABI) reaching the level from $3.01 \pm 0.82$ points ("pathological level") to $9.44 \pm 0.3^{*}$ ("light dysfunctional") within significance of $\mathrm{p}<0.001$; 2) Study Group 2 (ADD/ADHD) from $8.332 \pm 1.3$ points ("lightly dysfunctional") to $15.84 \pm 0.6^{*}$ ("function but low level of development") with p < 0.05; 3) Study Group 3 (anxiety, post-trauma and PTSD) from $7.33 \pm 1.23$ ("dysfunctional") to $14.72 \pm 0.8^{\star}$ points ("functional but low level of development") with $\mathrm{p}<0.001$; 4) Study Group 4 (ASD) from $5.62 \pm 0.7$ points ("severe dysfunctional level") to $13.89 \pm 0.2$ points ("functional, but very low level of development") with $\mathrm{p}<0.001$. Improvement of every reflex pattern of individuals in each group is also statistically significant within $\mathrm{p}<0.05$ (Table 2 and Table 3). Table 2 shows the Diagnostic Quality Features (X1 - X30) within body movement planes ( $\mathrm{S}=$ sagittal; $\mathrm{H}$ = horizontal; $\mathrm{D}=$ dorsal), levels of reflex development, and Assessments results before and after participation in MNRI integration therapy in the Study Group. Note: “»” equals statistical significance at $\alpha=0.001$ level.

This data on reflex patterns before and after was also reviewed with comparative analysis of average values and standard deviations with three synthetic variables: $Z_{S}$ (sagittal body plane), $Z_{H}$ (horizontal), and $Z_{D}$ (dorsal) and $Z_{C}$ (cumulative). Pre- and post-tests levels of reflex pattern development in four study groups and Control Group, demonstrated statistically significant changes in every cluster of reflexes for individuals in study groups after the MNRI reflex repatterning program (at $\alpha=0.05$ ) vs. no statistically significant findings in Control Group ( $\mathrm{p}$ values > 0.05), where individuals did not receive the MNRI training. The results in Table 3 were validated statistically using data on a level of synthesized function $\mathrm{Z}=\mathrm{f}(\mathrm{x})$ [48] as well as the nonparametric comparison of two variables by Wilcoxon Matched Pairs test (at $\alpha=0.001$ ). The statistical 
Table 2. Results of Reflex Assessment of Individuals with Neurological Deficits in Study Group $(\mathrm{n}=310)$ compared to Individuals with Neurotypical Development in Control Group $2(\mathrm{n}=241)$.

\begin{tabular}{|c|c|c|c|c|c|c|c|c|c|c|c|c|}
\hline \multirow{3}{*}{ 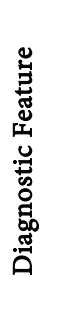 } & \multirow{3}{*}{ 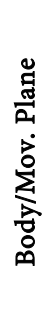 } & \multirow{3}{*}{ Reflex } & \multicolumn{10}{|c|}{$\begin{array}{l}\text { Reflex Profile of individuals with Neurological Deficits }(n=310) \\
\text { Results before and after the MNRI }{ }^{\circledR} \text { Program (in } 9 \text { days) in Groups: }\end{array}$} \\
\hline & & & $\begin{array}{l}\mathrm{CP}, \mathrm{Se} \\
\mathrm{TBI} \text { an }\end{array}$ & $\begin{array}{l}\text { eizure, } \\
\text { nd ABI }\end{array}$ & \multicolumn{2}{|c|}{ ADD/ADHD } & \multicolumn{2}{|c|}{$\begin{array}{c}\text { Anxiety disorder, } \\
\text { Post-trauma and PTSD }\end{array}$} & \multicolumn{2}{|c|}{ Autism disorder } & \multicolumn{2}{|c|}{$\begin{array}{l}\text { Neurotypical } \\
\text { Development }\end{array}$} \\
\hline & & & $\begin{array}{l}\text { Study C } \\
\qquad(\mathrm{n}=\end{array}$ & $\begin{array}{l}\text { Group } 1 \\
=49)\end{array}$ & $\begin{array}{l}\text { Study } C \\
\quad(\mathrm{n}=\end{array}$ & $\begin{array}{l}\text { Group } 2 \\
104)\end{array}$ & $\begin{array}{l}\text { Study } \\
\qquad(\mathrm{n}=\end{array}$ & $\begin{array}{l}\text { Group } 3 \\
=62)\end{array}$ & $\begin{array}{l}\text { Study G } \\
\qquad(\mathrm{n}=\end{array}$ & $\begin{array}{l}\text { Group } 4 \\
=95)\end{array}$ & $\begin{array}{r}\text { Control } \\
\text { No MNRI }\end{array}$ & $\begin{array}{l}\text { Group } 5 \\
(n=241)\end{array}$ \\
\hline $\mathrm{X}_{1}$ & S & $\frac{\text { Core Tendon }}{\underline{\text { Guard }}}$ & $\underline{5.57 \pm 0.4}$ & $\underline{7.52 \pm 0.6^{*}}$ & $\underline{11.72 \pm 0.5}$ & $\underline{13.54 \pm 0.7^{\star}}$ & $\underline{7.87 \pm 0.37}$ & $\underline{9.52 \pm 0.8^{*}}$ & $\underline{11.87 \pm 0.3}$ & $13.52 \pm 0.7^{\star}$ & $15.5 \pm 0.5$ & $15.5 \pm 0.8$ \\
\hline $\mathrm{X}_{2}$ & $\mathrm{~S}$ & $\frac{\text { Robinson }}{\text { Hands Grasp }}$ & $\underline{5.2 \pm 0.3}$ & $\underline{7.31 \pm 0.7^{*}}$ & $\underline{11.62 \pm 0.8}$ & $\underline{13.31 \pm 0.7^{*}}$ & $\underline{10.6 \pm 0.4}$ & $\underline{12.31 \pm 0.7^{\star}}$ & $\underline{6.6 \pm 0.4}$ & $\underline{7.71 \pm 0.5^{\star}}$ & $16.8 \pm 0.7$ & $16.7 \pm 0.65$ \\
\hline $\mathrm{X}_{3}$ & $\mathrm{~S}$ & $\frac{\text { Hands }}{\text { Pulling }}$ & $\underline{4.54 \pm 0.5}$ & $\underline{6.07 \pm 0.3^{*}}$ & $\underline{11.54 \pm 0.5}$ & $\underline{14.07 \pm 0.6^{*}}$ & $\underline{9.54 \pm 0.5}$ & $\underline{11.07 \pm 0.3^{*}}$ & $\underline{5.54 \pm 0.8}$ & $\underline{7.07 \pm 0.3^{*}}$ & $16 \pm 0.45$ & $16.1 \pm 0.7$ \\
\hline $\mathrm{X}_{4}$ & $\mathrm{~S}$ & $\frac{\underline{\text { Babkin }}}{\underline{\text { Palmomental }}}$ & $4.11 \pm 0.72$ & $5.42 \pm 0.5$ & $12.11 \pm 0.8$ & $14.02 \pm 1.2$ & $8.11 \pm 0.8$ & $10.02 \pm 1.5$ & $5.51 \pm 0.7$ & $5.78 \pm 1.4$ & $16.5 \pm 0.8$ & $16,5 \pm 0.6$ \\
\hline $\mathrm{X}_{5}$ & S & $\underline{\text { Babinski }}$ & $\underline{4.11 \pm 0.4}$ & $\underline{5.52 \pm 0.7^{\star}}$ & $\underline{11.34 \pm 0.7}$ & $\underline{14.16 \pm 0.7^{*}}$ & $\underline{8.11 \pm 0.4}$ & $\underline{10.02 \pm 0.8^{*}}$ & $\underline{6.51 \pm 0.7}$ & $\underline{8.02 \pm 0.6^{*}}$ & $15.9 \pm 0.77$ & $16.5 \pm 1.3$ \\
\hline $\mathrm{X}_{6}$ & S & Foot Grasp & $4.33 \pm 1.2$ & $5.76 \pm 0.7$ & $\underline{11.02 \pm 0.7}$ & $\underline{13.26 \pm 0.7^{*}}$ & $\underline{8.55 \pm 0.6}$ & $\underline{9.79 \pm 0.4^{*}}$ & $\underline{6.55 \pm 0.5}$ & $\underline{7.85 \pm 0.5^{\star}}$ & $15.3 \pm 0.5$ & $15 \pm 0.8$ \\
\hline $\mathrm{X}_{7}$ & $\mathrm{~S}$ & $\begin{array}{r}\text { Leg Cross } \\
\text { Flex. }- \text { Exten. }\end{array}$ & $4.09 \pm 0.72$ & $5.52 \pm 1.8$ & $12.07 \pm 0.8$ & $14.32 \pm 0.8^{*}$ & $12.07 \pm 0.3$ & $13.52 \pm 0.4^{\star}$ & $8.07 \pm 0.9$ & $11.52 \pm 1.3^{*}$ & $16.8 \pm 0.9$ & $17.2 \pm 0.6$ \\
\hline $\mathrm{X}_{8}$ & $\mathrm{~S}$ & $\frac{\text { Asymmetr. }}{\text { Tonic Neck }}$ & $\underline{4.16 \pm 0.28}$ & $\underline{5.29 \pm 0.5^{*}}$ & $\underline{14.16 \pm 0.7}$ & $\underline{15.62 \pm 0.5^{*}}$ & $\underline{12.2 \pm 0.3}$ & $\underline{13.86 \pm 0.3^{*}}$ & $\underline{12.7 \pm 0.54}$ & $13.86 \pm 0.4^{*}$ & $17.5 \pm 0.9$ & $17.4 \pm 1.3$ \\
\hline $\mathrm{X}_{9}$ & $\mathrm{~S}$ & $\frac{\text { Abdominal }}{\text { Sleep Posture }}$ & $\underline{5.15 \pm 0.4}$ & $\underline{6.78 \pm 0.3^{*}}$ & $8.33 \pm 1.3$ & $9.76 \pm 1.2$ & $7.33 \pm 1.23$ & $8.76 \pm 0.68$ & $7.47 \pm 0.7$ & $8.56 \pm 0.61$ & $16.4 \pm 1.4$ & $16.3 \pm 0.7$ \\
\hline $\mathrm{X}_{10}$ & $\mathrm{~S}$ & Bonding & $8.86 \pm 0.7$ & $10.68 \pm 0.5$ & $13.78 \pm 0.8$ & $14.98 \pm 0.7$ & $9.86 \pm 0.7$ & $10.68 \pm 0.7$ & $8.86 \pm 0.53$ & $8.97 \pm 0.52$ & $15.6 \pm 0.8$ & $15.5 \pm 0.7$ \\
\hline $\mathrm{X}_{12}$ & $\mathrm{H}$ & $\underline{\text { Bauer Crawling }}$ & $\underline{4.26 \pm 0.56}$ & $\underline{6.11 \pm 0.7^{*}}$ & $\underline{11.23 \pm 0.8}$ & $\underline{13.43 \pm 0.9^{*}}$ & $\underline{9.24 \pm 0.58}$ & $\underline{11.01 \pm 0.68^{*}}$ & $\underline{9.33 \pm 0.7}$ & $\underline{11.56 \pm 0.6^{*}}$ & $15.5 \pm 0.6$ & $15.5 \pm 0.8$ \\
\hline $\mathrm{X}_{13}$ & $\mathrm{H}$ & Moro Embrace & $\underline{5.23 \pm 0.6}$ & $\underline{6.8 \pm 0.68^{*}}$ & $\underline{11.23 \pm 0.8}$ & $\underline{13 \pm 0.5^{*}}$ & $\underline{6.83 \pm 0.6}$ & $\underline{11.65 \pm 0.6^{*}}$ & $\underline{8.73 \pm 0.56}$ & $\underline{11.8 \pm 0.61^{\star}}$ & $15.5 \pm 0.52$ & $15.5 \pm 0.8$ \\
\hline $\mathrm{X}_{14}$ & $\mathrm{H}$ & $\underline{\text { Fear Paralysis }}$ & $\underline{4.9 \pm 0.15}$ & $\underline{6.25 \pm 0.6^{*}}$ & $\underline{11.84 \pm 0.7}$ & $\underline{13.45 \pm 0.7^{*}}$ & $\underline{6.87 \pm 0.5}$ & $\underline{10.25 \pm 0.8^{*}}$ & $\underline{8.56 \pm 0.45}$ & $10.35 \pm 0.6^{*}$ & $14.5 \pm 0.5$ & $14.6 \pm 0.7$ \\
\hline $\mathrm{X}_{15}$ & $\mathrm{H}$ & $\frac{\text { Hands }}{\text { Supporting }}$ & $\underline{3.64 \pm 0.23}$ & $\underline{4.35 \pm 0.3^{*}}$ & $\underline{12.64 \pm 0.3}$ & $\underline{14.75 \pm 0.4^{*}}$ & $\underline{8.54 \pm 0.8}$ & $\underline{10.77 \pm 0.5^{\star}}$ & $8.64 \pm 0.3$ & $9.75 \pm 0.8$ & $15.5 \pm 0.6$ & $15.5 \pm 0.9$ \\
\hline $\mathrm{X}_{16}$ & $\mathrm{H}$ & $\frac{\text { Segmental }}{\text { Rolling }}$ & $4.67 \pm 0.6$ & $5.12 \pm 1.3$ & $13.44 \pm 0.7$ & $14.22 \pm 0.4$ & $7.67 \pm 0.82$ & $11.21 \pm 1.3^{\star}$ & $6.47 \pm 0.6$ & $7.21 \pm 0.8$ & $15.6 \pm 0.8$ & $15.5 \pm 1.2$ \\
\hline $\mathrm{X}_{17}$ & $\mathrm{H}$ & $\underline{L a n d a u}$ & $\underline{4.22 \pm 0.4}$ & $\underline{4.45 \pm 0.2}$ & $\underline{11.54 \pm 0.4}$ & $\underline{13.75 \pm 0.2^{*}}$ & $\underline{7.93 \pm 0.7}$ & $\underline{9.84 \pm 0.9^{*}}$ & $\underline{8.52 \pm 0.36}$ & $\underline{9.75 \pm 0.4^{*}}$ & $15.3 \pm 0.65$ & $15.1 \pm 1.1$ \\
\hline $\mathrm{X}_{18}$ & $\mathrm{H}$ & $\frac{\text { Flying and }}{\underline{\text { Landing }}}$ & $\underline{3.01 \pm 0.82}$ & $\underline{3.66 \pm 0.5}$ & $\underline{13.04 \pm 0.8}$ & $\underline{14.74 \pm 0.5^{*}}$ & $\underline{11.01 \pm 0.7}$ & $\underline{12.94 \pm 0.7^{*}}$ & $\underline{9.01 \pm 0.8}$ & $10.66 \pm 0.5^{*}$ & $14.6 \pm 0.7$ & $14.4 \pm 0.8$ \\
\hline $\mathrm{X}_{19}$ & $\mathrm{H}$ & Grounding & $\underline{4.18 \pm 0.6}$ & $\underline{5.24 \pm 0.3^{*}}$ & $\underline{11.78 \pm 0.5}$ & $\underline{13.24 \pm 0.3^{*}}$ & $\underline{9.74 \pm 0.6}$ & $\underline{11.34 \pm 0.7^{\star}}$ & $\underline{9.62 \pm 0.72}$ & $11.24 \pm 0.6^{*}$ & $15.8 \pm 0.6$ & $15.6 \pm 0.9$ \\
\hline $\mathrm{X}_{20}$ & $\mathrm{H}$ & Head Righting & $\underline{5.27 \pm 0.5}$ & $\underline{6.34 \pm 0.4^{*}}$ & $\underline{14.58 \pm 0.5}$ & $\underline{15.94 \pm 0.7^{*}}$ & $\underline{12.52 \pm 0.5}$ & $\underline{14.36 \pm 0.9^{*}}$ & $\underline{11.34 \pm 0.6}$ & $\underline{12.44 \pm 0.4^{*}}$ & $16.7 \pm 0.7$ & $16.7 \pm 1.4$ \\
\hline $\mathrm{X}_{21}$ & $\mathrm{D}$ & $\frac{\text { Trunk }}{\text { Extension }}$ & $\underline{5.18 \pm 0.47}$ & $\underline{6.28 \pm 0.21^{*}}$ & $\underline{13.38 \pm 0.3}$ & $\underline{14.87 \pm 0.5^{*}}$ & $\underline{12.5 \pm 0.4}$ & $\underline{13.65 \pm 0.4^{*}}$ & $\underline{12.28 \pm 0.3}$ & $\underline{13.98 \pm 0.2^{*}}$ & $16.5 \pm 0.7$ & $16.2 \pm 0.8$ \\
\hline $\mathrm{X}_{22}$ & $\mathrm{D}$ & $\frac{\text { Symmetr. Tonic }}{\underline{\text { Neck }}}$ & $\underline{4.24 \pm 0.17}$ & $\underline{5.63 \pm 0.6^{*}}$ & $\underline{9.58 \pm 0.7}$ & $\underline{12.13 \pm 0.6^{*}}$ & $\underline{8.65 \pm 0.7}$ & $\underline{13.23 \pm 0.7^{\star}}$ & $\underline{6.58 \pm 0.7}$ & $\underline{8.13 \pm 0.4^{*}}$ & $16 \pm 0.6$ & $15.8 \pm 0.9$ \\
\hline $\mathrm{X}_{23}$ & $\mathrm{D}$ & Spinal Galant & $\underline{5.1 \pm 0.4}$ & $\underline{6.59 \pm 0.5^{*}}$ & $\underline{9.1 \pm 0.54}$ & $\underline{11.19 \pm 0.8^{*}}$ & $\underline{9.82 \pm 1.3}$ & $\underline{12.37 \pm 0.9^{*}}$ & $\underline{7.1 \pm 0.47}$ & $\underline{9.19 \pm 0.8^{*}}$ & $15 \pm 0.84$ & $15.3 \pm 1.2$ \\
\hline $\mathrm{X}_{24}$ & $\mathrm{D}$ & Spinal Perez & $\underline{4.12 \pm 0.4}$ & $\underline{5.7 \pm 0.68^{*}}$ & $\underline{11.42 \pm 0.5}$ & $\underline{13.13 \pm 0.7^{*}}$ & $\underline{11.24 \pm 0.4}$ & $\underline{12.3 \pm 0.3^{*}}$ & $8.12 \pm 0.8$ & $9.3 \pm 1.5$ & $16.5 \pm 0.7$ & $16.4 \pm 1.2$ \\
\hline
\end{tabular}




\section{Continued}

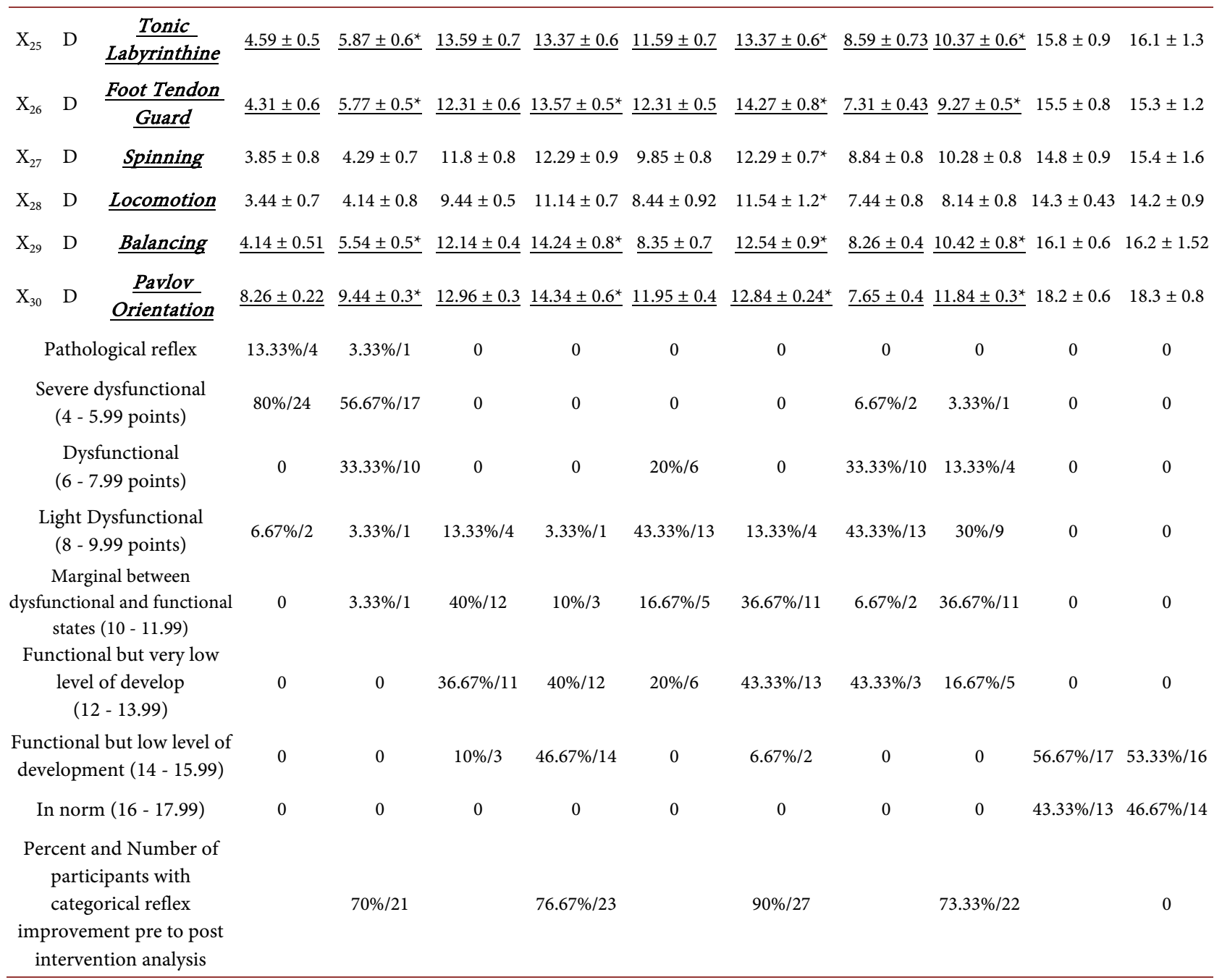

Table 3. Results of comparative analysis of average values and standard deviations with three synthetic variables: $\mathrm{Z}_{\mathrm{S}}$ (sagittal body plane), $\mathrm{Z}_{\mathrm{H}}$ (horizontal), and $\mathrm{Z}_{\mathrm{D}}$ (dorsal) and $\mathrm{Z}_{\mathrm{C}}$ (cumulative) in pre- and post-tests levels of reflex patterns development.

\begin{tabular}{|c|c|c|c|c|c|c|}
\hline \multicolumn{7}{|c|}{$\begin{array}{l}\text { Average values and standard deviations for three synthetic variables: } \\
\qquad Z_{S} \text { (sagittal body plane), } Z_{H} \text { (horizontal), and } Z_{D} \text { (dorsal) }\end{array}$} \\
\hline \multirow{3}{*}{ Groups } & \multirow{3}{*}{ Variables } & \multicolumn{4}{|c|}{ Before and after the MNRI intervention } & \multirow{3}{*}{$\begin{array}{l}\text { ANOVA } \\
\mathrm{p} \text { value less than }\end{array}$} \\
\hline & & \multicolumn{2}{|c|}{ Before } & \multicolumn{2}{|c|}{ After } & \\
\hline & & Mean & S.D. & Mean & S.D. & \\
\hline \multirow{4}{*}{$\begin{array}{c}\text { Study Group } 1 \\
\text { CI, seizures, TBI, } \\
\text { ABI }(\mathrm{n}=49)\end{array}$} & $\mathrm{Z}_{\mathrm{C}}$ & 0.4222 & 0.0223 & 0.7156 & 0.0214 & 0.001 \\
\hline & $Z_{S}$ & 0.4123 & 0.0213 & 0.6954 & 0.0255 & 0.001 \\
\hline & $\mathrm{Z}_{\mathrm{H}}$ & 0.3955 & 0.0176 & 0.7127 & 0.0215 & 0.001 \\
\hline & $Z_{D}$ & 0.4247 & 0.0213 & 0.7418 & 0.0211 & 0.001 \\
\hline \multirow{3}{*}{$\begin{array}{l}\text { Study Group } 2 \\
\text { ADD/ADHD } \\
(\mathrm{n}=104)\end{array}$} & $\mathrm{Z}_{\mathrm{C}}$ & 0.4172 & 0.1752 & 0.4377 & 0.1765 & 0.05 \\
\hline & $\mathrm{Z}_{\mathrm{S}}$ & 0.3765 & 0.1627 & 0.3654 & 0.1693 & 0.05 \\
\hline & $\mathrm{Z}_{\mathrm{H}}$ & 0.4246 & 0.1843 & 0.4377 & 0.1975 & 0.05 \\
\hline
\end{tabular}




\section{Continued}

\begin{tabular}{ccccccc}
\hline & $\mathrm{Z}_{\mathrm{D}}$ & 0.3933 & 0.1764 & 0.3876 & 0.1876 & 0.05 \\
$\begin{array}{c}\text { Study Group 3 } \\
\text { Anxiety, }\end{array}$ & $\mathrm{Z}_{\mathrm{C}}$ & 0.4162 & 0.0654 & 0.8765 & 0.0723 & 0.001 \\
$\begin{array}{c}\text { post-trauma, PTSD } \\
\text { (n = 62) }\end{array}$ & $\mathrm{Z}_{\mathrm{H}}$ & 0.3697 & 0.0765 & 0.9879 & 0.0652 & 0.001 \\
& $\mathrm{Z}_{\mathrm{D}}$ & 0.3987 & 0.0765 & 0.698 & 0.0592 & 0.001 \\
& $\mathrm{Z}_{\mathrm{C}}$ & 0.4275 & 0.1564 & 0.4434 & 0.0691 & 0.05 \\
$\begin{array}{c}\text { Study Group 4 } \\
\text { Autism (n=95) }\end{array}$ & $\mathrm{Z}_{\mathrm{S}}$ & 0.4556 & 0.1432 & 0.4765 & 0.0578 & 0.05 \\
& $\mathrm{Z}_{\mathrm{H}}$ & 0.4356 & 0.1834 & 0.4435 & 0.0795 & 0.05 \\
& $\mathrm{Z}_{\mathrm{D}}$ & 0.3877 & 0.0879 & 0.4287 & 0.0924 & 0.05 \\
& $\mathrm{Z}_{\mathrm{C}}$ & 0.2812 & 0.1657 & 0.3243 & 0.1543 & 0.5 \\
$\begin{array}{c}\text { Control Group 2 (n } \\
\text { 241) Neurotypical }\end{array}$ & $\mathrm{Z}_{\mathrm{S}}$ & 0.2967 & 0.1734 & 0.3187 & 0.1734 & 0.5 \\
development & $\mathrm{Z}_{\mathrm{H}}$ & 0.2962 & 0.1487 & 0.2765 & 0.1639 & 0.5 \\
& $\mathrm{Z}_{\mathrm{D}}$ & 0.3155 & 0.1145 & 0.3276 & 0.1274 & 0.5 \\
\hline
\end{tabular}

evaluation of the data demonstrates significant changes in all synthesized variables (with 10 reflex patterns in each) and a high degree of effectiveness for the MNRI program.

This quantitative study is based on the pre and post test scores from 310 individuals who attended the MNRI Family conferences from January 2016 to January 2018. The Reflex Assessment was administered to all individuals by the same specialist. Analysis of the data shows several important facts. The level of improvement of reflex functionality is dependent on the severity of neurological deficits.

The highest progress in improvement of the level of reflex patterns is noted in: Study Group 3 (anxiety, post-trauma and PTSD) - 90\% (27 of 30) reflex patterns increased in level of their functionality. Study Group 2 (ADD/ADHD) - 76.67\%/23 patterns, and Study Group 4 (ASD)-73.33\% (22 out of 30 patterns) also demonstrated positive changes in reflex pattern functionality. Reflex patterns in the Study Group 1 (CP, seizures, TBI, ABI) improved in 70\% (21 out of 30) of reflex patterns. These findings all demonstrated improvement within the 8 days of implementing the program, which suggests the (Table 3) effectiveness of modelling the length and content of the MNRI program (intensive MNRI Family Conferences, homework, local MNRI Therapy intervention attendance) according to the nature of deviations in reflex patterns and neurological deficits in individuals.

Assessment of reflex patterns before and after the MNRI intensive therapy work with all four study groups showed significant improvements vs. the Control Group of healthy individuals with typical development. The Control Group was administered the pre- and post-test and did not receive the intensive work. The Control Group did not demonstrate significant changes in their reflex scores. This fact strongly suggests the positive effect of the MNRI Therapy mod- 
ality for improving the functioning of the assessed reflex patterns through optimization of regulatory functions of the HPA-stress-axis and its effects on stress resiliency.

\section{Discussion}

1) The study results of Physiological Markers of individuals have been grouped into four systems of the body: the respiratory system, cardiovascular system, digestive system, and the nervous system.

The respiratory system which includes the pulse oximeter readings, breath sounds, and peak flow were examined in order to identify symptoms and reasons for discovering why this marker has a lower level in neuroatypical individuals. It has been demonstrated earlier that breathing movements in mammals are driven by rhythmic neural activity generated within spatially and functionally organized brainstem neural circuits comprising the respiratory central pattern generator [29], and that this rhythmic activity provides homeostatic regulation of gases in blood and tissues and integrates breathing with other motor acts [49]. Breathing movement marker demonstrated significant improvement after the MNRI Reflex Integration Program in three study groups and in all groups together overall. Specifically, an average increase for lung sounds from $88.95 \pm 3.1$ in pre-test to $97.17 \pm 4.9$ in post-test at $p<0.05$ evidenced an increase of ability to breathe and utilize upper, middle, and lower lobe for inspiration and expiration in individuals in our research.

Peak flow test was used to analyze how well the lungs of individuals were working. Stress, inflammation of airways, allergies, respiratory muscle weakness, and asthma are all factors that were attributing to lower readings [29] [49]. The peak flow in post-test demonstrated improvement with an average of $266.97 \pm$ 18.8 from initial $216.01 \pm 14.7$ in pre-test at $\mathrm{p}<0.05$. It is important to note that this average increase includes the $21 \%$ of participants who were unable to perform peak flow, pre-conference. This increase is indicative of improvement of the respiratory system after the MNRI therapy sessions. The improvement of this marker in individuals can be attributed to the enhancement of accessory muscles, flexibility of the ribs, and the diaphragm. By increasing the residual lung capacity, the potential for better oxygenation and perfusion of all organs and body tissues leads to greater health benefits and functional abilities for the respiratory system.

The cardiovascular system delivering blood to tissues and vital organs while carrying oxygen and nutrients that are needed to keep cells alive

(https://www.ama-assn.org) was also improved in individuals in this study after the MNRI work. Particularly the marker of pulse has improved to an average of $79.9 \pm 3.3$ in comparison with pre-test result of $86.52 \pm 3.5$ at $\mathrm{p}<0.05$. Diastolic blood pressure had some reduction on average of $64.5 \pm 3.3$ in pre-test and 66.67 \pm 3.3 in post-test in pre-test at $\mathrm{p}<0.05$, which although is a tendency for improvement, reflects a decrease in stress whether that be physiological or emotional. 
The dorsalis pedis marker shows an increase to an average of $97.65 \pm 4.1$ from previous $86.9 \pm 3.6$ in test at $\alpha=0.05$ ), and posterior tibial pulses also improved to achieve the mean level of $98.43 \pm 4.6$ from the initial mean level of $87.3 \pm 3.4$ in pre-test at $\alpha=0.05$. This data is indicative of an increase in the overall blood supply to the peripheral extremities.

The digestive system metabolizes our food into energy, nutrients, and waste. Morisava, et al. described that the intestine is composed of smooth muscle in which stretch stimulation of the intestine depolarizes the smooth muscle cell membrane potential and increases the action potential, resulting in muscle contraction, which is called stretch induced contraction [50]. The intestinal peristalsis was assessed by use of auscultation of the bowel sounds. Auscultation of bowel sounds is a quick and low-cost examination, it has been used for more than 150 years to assess various abdominal conditions [51] [52] [53]. The Bowel Sound Score increased from an average of $98.9 \pm 4.5$ from initial $62.25 \pm 2.8$ in post-test in pre-test at $\mathrm{p}<0.05$. Note that $53.6 \%$ of the total study participants presented within the range of normal score after receiving the MNRI program.

A total of $93.5 \%$ of 310 participants showed improvement by shifting from either hypo- or hyper-active to normal active. Hypoactive bowels sounds can be a sign that their motility is slowed, which can indicate constipation. Hyperactive sounds mean there is an increased intestinal activity which can indicate diarrhea or other digestive illnesses. The analysis of results in post-tests after the MNRI program show that regulation of the digestive system has been established, which is essential because it plays an important role with excretion of waste, gut health, and absorption of nutrients. Morisava, et al. [50] [51] indicated that under stress the sympathetic system, is increasingly active, and the digestive system is inhibited. MNRI study findings demonstrated evidence that the bowel system is responding in a positive matter towards regulation and healthy function of intestinal system.

The respiratory marker (Breath Sound Score) demonstrates a change in this marker, which is of an average of $97.17 \pm 4.9$ (in comparison with initial $88.95 \pm$ 3.1 at $\alpha=0.05$ ). This data shows improved breathing in the cohort of individuals in this research, and particularly the improvement of their inspiration and expiration cycle. Change in sounds shows strikeout activation of peak flow and $\mathrm{O} 2$ supply increase, and also at improved pitch and duration of breathing cycle based also on other corresponding studies [15] [54].

The PERRLA marker. In this study the test for the eye responses of individuals with challenged development to light and accommodation has been used. This marker serves as an indication of the healthy functioning of both the visual and entire nervous system. "Neurologic changes can be reflected in pupil responses" [54] [55]. Pupil response also serves for the evaluation of Cranial Nerves 2, 3, 4 and 6 [55] [56] [57]. The reactivity of the pupils to light had an average increase and more importantly, the ability to accommodate, which increased by $98.52 \pm 3.5$ vs. $88.2 \pm 2.9 \alpha=0.05$ in pre-test. The ability to accommodate in- 
creased by an average of 74.62 at $\alpha=0.05$. PERRLA results in post-tests demonstrate signs of normalization and proper function of this aspect of the neurological system, confirming the significant impact of MNRI towards the participants' visual responsiveness.

It is important to note, that the cranial nerves 3, 4, and 6 are directly associated with eye movement, and provide insight into the pretectal area of the brain responsible for maturation of visual reflexes. These include ocular-vestibular and optokinetic patterns, adjustment of eye movements, visual image dynamics and vestibular system. The results of this study demonstrated that after eight days of MNRI improvement in movement of the eyes which indicate that Cranial Nerve 3 (Oculomotor) for eye movements up, down, adduction and medial, Cranial Nerve 4 (Trochlear) for innervating the superior oblique muscle, and Cranial Nerve 6 (Abducens Nerve) responsible for innervations of lateral rectus muscle of the eye, and lateral adduction of eye movement also improved.

2) Results of correlative analysis of Physiological Markers and Reflex functions. The results of the post-evaluation of reflex patterns after the MNRI programs for both the physiological marker and reflex function showed significant correlation with results of changes in standard physiological markers in all four groups of individuals with neurological deficits at $\alpha=0.05$.

The results of this study suggest the hypothesis that physiological markers and reflexes are interrelated and potentially interdependent phenomena. Improvement in reflex patterns positively affects the physiological vital markers, which may positively influence regulation of the HPA-stress-axis and increase stress resiliency.

\section{Conclusions}

The present findings suggest that the study recipients who received the MNRI treatment demonstrated marked improvements in standard vitals. These results are indicative of a trend towards homeostasis, the body's ability to regulate the balance between negative stress and free and relaxed states, and normalization of the work of the HPA stress-axis. MNRI's impact on these body systems shows a trend towards the body's internal changes allowing optimization of body functioning to transpire. These results suggest that the MNRI Program is a safe, advantageous, and non-pharmaceutical therapy that brings marked physiological change to the body's internal systems. Earlier studies also demonstrated similar results showing that the MNRI tools adjunctively improved the therapeutic effectiveness of pharmacological treatments in bronchitis and other [31] [32] [58].

The effect of the Masgutova Reflex Integration Method on physical markers of individuals with neurodevelopmental deficits (CP, seizure, TBI and ABI; $\mathrm{ADD} / \mathrm{ADHD}$; ASD) and post-trauma (anxiety, post-traumatic experience and PTSD) found 8 out of 15 (53.33\%) physiological markers on the pre-test demonstrated poor functioning. After 8 days of active treatment intervention (six 50-minute sessions each day), post-tests of physiological markers and reflex 
analysis demonstrated statistically significant improvement in multiple parameters. This effect is interpreted due to reducing participant perceived stress and rapid improvement of the homeostasis of the body's specific systems: respiratory, cardiovascular, digestive, and nervous. The improvement in physiological markers is indicative of the 9 out of $15(60.0 \%)$ reflex patterns that were shown to have statistically significant changes in all four study groups. The control group, who did not receive the MNRI Program did not demonstrate improvement on post-test results. The positive results found between the pre and post assessments indicated that the MNRI Reflex Integration work with dysfunctional reflex patterns affected the normalization of reflexes in 23 out of $30(77.5 \%)$ reflex patterns.

The results of this study indicate that the MNRI reflex integrative techniques may lead to a reduction of perceived stress and negative factors blocking physiological health homeostasis, which decreases protective neurological responses thus limiting perception, and causes dysregulation in behaviors and emotions, especially after traumatic events. Improvements in the functions of reflex patterns positively affect survival mechanisms, increase stress resiliency, and support overall neurophysiological and neuro-psychological aspects of health and well-being in individuals with neurological deficits. The comparative data analysis of participants reveals that the level of improvement of reflex functionality is dependent on the severity of neurological deficits and indicates the need to continue individualized MNRI Programs according to the diagnosis and severity of the neurological deficits.

\section{Ethical Approval}

This study was approved by New England IRB (\#: 20160464, Legacy IRB\#: 15-466, Action Date: 02/11/2016; A WIRB Copernicus Group Company). All specialists leading the evaluations were certified by the NIH (National Institute of Health, Office of Extra Mutual Research) "Protecting Human Research Participants" in 2012-2017. All participants were assigned codes to protect anonymity. Receipt of informed consent was received from all participants' parent or legal guardian. MNRI Assessments were conducted and treatment administered by designated Specialists or MNRI Core Specialists who have successfully completed the requirements for Continuing Professional Education in MNRI and clinical hours (https://masgutovamethod.com/). Double blind analysis of research results and preparation of this report is done by independent experts. This study is a New England IRB approved study (\#: 20160464, Legacy IRB\#: 15-466).

\section{Conflicts of Interest}

The authors declare no conflicts of interest regarding the publication of this paper.

\section{References}

[1] SMEI (2015) Reflexes of the Brain: Portal to Neurodevelopment and Learning. 
Florida, $486 \mathrm{p}$.

[2] Sechenov, I.M. (2012) Physiology of Behavior. Scientific Works. M. G. Jaroshevsky, Moscow.

[3] Pavlov, I. (1960) Conditioned Reflexes: An Investigation of the Physiological Activity of the Cerebral Cortex. Dover Publications Inc., New York, NY.

[4] Sherrington, C. (1947) The Integrative Action of the Nervous System. Cambridge University Press, London.

[5] Luria, A.R. (1969) High Cerebrum Functions of the Human and Their Disorders in Cases of Local Damages. Moscow State University, Moscow.

[6] Asratian, E.A. (1983) Selected Works. Reflexive Theory of High Nerve System Activity. Science, Moscow, 328 p.

[7] Haines, D.E. (2013) Fundamental Neuroscience for Basic and Clinical Application. 4th Edition, Elsevier Saunders, Philadelphia, PA.

[8] Lundy-Ekman, L. (2002) Neuroscience: Fundamentals for Rehabilitation. 2nd Edition. Pacific University, Forest Grove, OR.

[9] Doidge, N. (2017) The Brain That Changes Itself: Stories of Personal Triumph from the Frontiers of Brain Science. ReadHowYouWant, Strawberry Hills.

[10] Merzenich, M.M. (2013) Soft-Wired: How the New Science of Brain Plasticity Can Change Your Life. Parnassus, San Francisco, CA.

[11] Ayres, J. (1971) Characteristics of Types of Sensory Integrative Functions. The American Journal of Occupational Therapy, 25, 329-334.

[12] Ayres, J. (1975) Sensory Integration and the Child. Western Psychological Services, Los Angeles.

[13] Vojta, V. (1989) Die Posturale Ontogenese als Basis der Entwicklungsstorungen. Monatsschr. Kinderheilkd, 141, 639-642.

[14] Semionova, K.A. (1999) Rehabilitation Treatment of the CP Patients in Residual State. Moscow.

[15] Akhmatova, N., Masgutova, S., Shubina, I., Akhmatov, E., Khomenkov, V., et al. (2015) Immunological Effects of Masgutova Neurosensorimotor Reflex Integration in Children with Recurrent Obstructive Bronchitis. International Journal of Neurorehabilitation, 2, 166-175.

[16] Masgutova, S. and Masgutov, D. (2015) MNRI Assessment for Determining the Level of Reflex Development. In: Reflexes. Portal to Neurodevelopment and Learning: A Collective Work, Svetlana Masgutova Educational Institute, Orlando, 201.

[17] Anokhin, P.K. (1974) Biology and Neurophysiology of the Conditioned Reflex and Its Role in Adaptive Behavior. In the Series: Cerebrovisceral and Behavioral Physiology and Conditioned Reflexes.

[18] Sechenov, I.M. (1863) Reflexes of the Brain. MIT Press, Cambridge.

[19] Piaget, J. (1976) The Grasp of Consciousness: Action and Concept in the Young Child. Harvard, Cambridge.

[20] Vygotsky, L. (1986) The Child Psychology. The Problems of Child Development. Pedagogika, Moscow.

[21] Bernstein, N. (1997) Bio-Mechanics and Physiology of Movement. Moscow-Voroniez, Moscow.

[22] Lewis, M. (2014) The Rise of Consciousness and the Development of Emotional Life. Guilford Press, New York. 
[23] Montessori, M. (1995) The Absorbent Mind. Henry Holt and Company, New York.

[24] Goldberg, E. (2001) The Executive Brain: Frontal Lobes and the Civilized Mind. Oxford University Press, New York.

[25] Bobath, K. and Bobath, B. (1984) The Neurodevelopmental Treatment. In: Scrutton, D., Ed., Management of the Motor Disorders of Children with Cerebral Palsy, Blackwell Scientific Publications Ltd., Oxford, 6-18.

[26] Kollen, B.J., Lennon, S., Lyons, B., et al. (2009) The Effectiveness of the Bobath Concept in Stroke Rehabilitation. Stroke, 40, e89-e97. https://stroke.ahajournals.org/content/40/4/e89.full.pdf+html https://doi.org/10.1161/STROKEAHA.108.533828

[27] Varadharajulu, D.G., Shetty, D.L. and Sahoo, D.K. (2017) The Effect of Bobath Concept and Conventional Approach on the Functional Outcome in the Post Stroke Hemiplegic Individuals. IOSR Journal of Sports and Physical Education, 4, 10-14. https://doi.org/10.9790/6737-04021014

[28] Doman, G. (1974) What to Do about Your Brain-Injured Child. Revised. Square One Publishers, Garden City Park.

[29] Springer, J.Z., Tennant, R.S. and Kamangar, N. (2016) Pulmonary Examination Technique. https://emedicine.medscape.com/article/1909159-technique\#c2

[30] Anatomy \& Physiology. http://dlsii.com/blog/tag/anatomy-physiology

[31] Masgutova, S.K., Akhmatova, N.K. and Lebedinskaya, O.V. (2013) Clinical-Immunological Assessment of Therapy Effect of the Neuro-Sensory-Motor Integration Program of Reflex Patterns in Airway Chronic Inflammatory Diseases. Event Abstract. 15th International Congress of Immunology, Milan, 22-27 August 2013.

[32] Akhmatova, N. and Akhmatova, E. (2017) Influence of MNRI on the Immune Status of Children with Down Syndrome. Journal of Clinical \& Cellular Immunology, 7, 483. https://doi.org/10.4172/2155-9899.1000483

[33] Akhmatova, E., Akhmatova, N. and Masgutova, S. (2016) MNRI: Immunocorrective Effect on the Immune Status of Children with Down Syndrome. 17th Biennial Meeting of the Euopean Society for Immunodeficiencies, Barcelona, 21-24 September 2016, 259.

[34] Masgutova, S., Sadowska, L., Kowalewska, J., Masgutov, D., Akhmatova, N. and Filipowski, H. (2015) Use of a Neurosensorimotor Reflex Integration Program to Improve Reflex Patterns of Children with Down Syndrome. Journal of Neurology and Neurosciences, 6, 59. https://doi.org/10.21767/2171-6625.100059

[35] Pilecki, W., Masgutova, S., Kowalewska, J., Masgutov, D., Akhmatova, N., Sobieszczanska, M. and Kalka, D. (2012) The Impact of Rehabilitation Carried Out Using the Masgutova Neurosensorimotor Reflex Integration Method in Children with Cerebral Palsy on the Results of Brain Stem Auditory Potential Examinations. Advances in Clinical and Experimental Medicine, 21, 363-371.

[36] Pilecki, W., Kipinski, L., Szawrowicz-Pełka, T., Kałka, D. and Masgutova, S. (2013) Spectral Brain Mapping in Children with Cerebral Palsy Treated by the Masgutova Neurosensorimotor re Ex Integration Method. Journal of the Neurological Sciences, 333, e550.

[37] Koberda, J.L. and Akhmatova, N. (2016) Masgutova Neurosensorimotor Reflex Integration (MNRI) as a New form of Manual Neuromodulation Technique. Journal of Neurology and Neurobiology, 2, 5.

[38] Koberda, J.L., Akhmatova, N., Akhmatova, E., Bienkiewicz, A., Nowak, K. and Nawrocka, H. (2016) Masgutova Neurosensorimotor Reflex Integration (MNRI) Neu- 
romodulation Technique Induces Positive Brain Maps (QEEG) Changes. Journal of Neurology and Neurobiology, $2,4$.

[39] Masgutova, S., Akhmatova N., Sadowska L., Shackleford, P. and Akhmatov, E. (2016) Progress with Neurosensorimotor Reflex Integration for Children with Autism Spectrum Disorder. Journal of Autism and Developmental Disorders, 4, 14. http://masgutovamethod.com/_uploads/_media_uploads/_source/Journal-Of-Neur ology-Psychology-vol4-issue2.pdf

[40] Masgutova, S. (2016) Post-Trauma Recovery in Children of Newtown, CT Using MNRI Reflex Integration. Journal of Traumatic Stress Disorders \& Treatment, 5, 5. http://masgutovamethod.com/_uploads/_media_uploads/_source/Journal-Of-Trau matic-Stress-Disorders-Treatment-vol5-issue5.pdf

[41] Reilly, B.M. (2003) Physical Examination in the Care of Medical Inpatients: An Observational Study. Lancet, 362, 1100-1105. https://doi.org/10.1016/S0140-6736(03)14464-9

[42] Masgutova, S., Akhmatova, N. and Ludwika, S. (2016) Reflex Profile of Children with Down Syndrome Improvement of Neurosensorimotor Development Using the MNRI ${ }^{\oplus}$ Reflex Integration Program. International Journal of Neurorehabilitation, 3, 197. https://doi.org/10.4172/2376-0281.1000197

[43] Selye, H. (1987) Stress without Distress. Corgi, London, 137-146.

[44] Masgutova, S.K., Akhmatova, N.K. and Kiselevsky, M.V. (2008) Clinic-Immunological Assessment of Effect of the Therapy Program of Neuro-Sensory-Motor Integration of Reflex Patterns at Chronic Inflammatory Diseases of Respiratory System. Russian Immunology Journal, 2, 454-463.

[45] Masgutova, S.K., Akhmatova, N.K. and Lebedinskava, O.V. (2013) Clinical-Immunological Assessment of Therapy Effect of the Neuro-Sensory-Motor Integration Program of Reflex Patterns in Airway Chronic Inflammatory Diseases. Frontiers in Immunology, 4.

[46] Masgutova, S., Masgutov, D., Akhmatova, N. and Akhmatov, E. (2015) Neurophysiological Foundation of the MNRI Reflex Integration Program. In: Reflexes: Portal to Neurodevelopment and Learning, Svetlana Masgutova Educational Institute, Orlando, 31-40.

[47] Myles, B., Huggins, A., Rome-Lake, M., et al. (2003) Written Language Profile of Children and Youth With Asperger Syndrome: From Research to Practice. Education and Training in Mental Retardation and Developmental Disabilities, 38, 362-369.

[48] Krefft, A. (2007) Diagnosis of Functions of Invisible Phenomena (Statistic Mathematic Analysis). Ofycyna Wydawnicza Politechniki Wroclawskiej, Wrocław.

[49] Smith, J.C., Abdala, A.P.L., Borgmann, A., Rybak, I.A. and Paton, J.F.R. (2013) Brainstem Respiratory Networks: Building Blocks and Microcircuits. Trends in Neurosciences, 36, 152-162. https://doi.org/10.1016/j.tins.2012.11.004

[50] Morisawa, T., Takahashi, T. and Nishi, S. (2015) The Effect of a Physiotherapy Intervention on Intestinal Motility. Journal of Physical Therapy Science, 27, 165-168. https://doi.org/10.1589/jpts.27.165

[51] Suarez, K., et al. (2010) Psychological Stress and Self-Reported Functional Gastrointestinal Disorders. The Journal of Nervous and Mental Disease, 198, 226-229. https://doi.org/10.1097/NMD.0b013e3181d106bc

[52] Breum, B.M., Rud, B., Kirkegaard, T. and Nordentoft, T. (2015) Accuracy of Abdominal Auscultation for Bowel Obstruction. World Journal of Gastroenterology, 21, 10018-10024. https://doi.org/10.3748/wjg.v21.i34.10018 
[53] Hooker, C. (2004) An Essay on Intestinal Auscultation. Boston Medical and Surgical Journal, 1849, 1439-1440.

[54] Ramirez, J.M. and Baertsch, N. (2018) Defining the Rhythmogenic Elementpringers of Mammalian Breathing. Physiology, 33, 302-316. https://doi.org/10.1152/physiol.00025.2018

[55] Sanders, R.D. and Gillig, P.M. (2009) Cranial Nerves III, IV, and VI. Oculomotor Function. Psychiatry, 6, 34-39.

https://www.ncbi.nlm.nih.gov/pmc/articles/PMC2801485/

[56] Erickson, K.I., Gildengers, A.G. and Butters, M.A. (2013) Physical Activity and Brain Plasticity in Late Adulthood. Dialogues in Clinical Neuroscience, 15, 99-108.

[57] Masgutova, S., Akhmatova, N., Shubina, I. and Kiselevsky, M. (2014) Immunological Study of Effectiveness of MNRI Program on Respiratory Diseases. In: Reflexes of the Brain: Portal to Neurodevelopment and Learning, Svetlana Masgutova Educational Institute, Orlando, 110-114.

[58] Masgutova, S., Akhmatova, N. and Akhmatov, E. (2016) Neurosensorimotor Reflex Integration for Autism: A New Therapy Modality Paradigm. Journal of Pediatric Neurological Disorders, 2, 107.

https://www.omicsgroup.org/journals/neurosensorimotor-reflex-integration-for-au tism-a-new-therapymodality-paradigm-.pdf 